\title{
A New Method of Bio-Catalytic Surface Modification for Microbial Desalination Cell
}

\author{
Ummy Mardiana ${ }^{a^{*}}$, Christophe Innocent ${ }^{b}$, Marc Cretin $^{b}$, Buchari Bucharic $^{c}$ \\ ${ }^{a}$ Sekolah Tinggi Ilmu Kesehatan Bakti Tunas Husada Tasikmalaya, Jl. Cilolohan No 36, Tasikmalaya, West of Java Indonesia \\ ${ }^{b}$ Institut Européen des Membranes, Université de Montpellier, place E. Bataillon, 34293 Montpellier Cedex 5, France \\ 'Institut Teknologi Bandung, Jalan Ganesha 10 Bandung, West of Java Indonesia
}

\begin{abstract}
A microbial desalination cell (MDC) built on a modified surface has been studied for seawater desalination. The goal of this study is to provide and develop a seawater desalination system that does not require energy support by applying a modification of the anode as an electron acceptor. The different potential charges that occur between anode and cathode can serve as the driving force for electrodialysis of seawater, resulting in its desalination. Yeast has been applied as a biocatalyst and neutral red has been chosen as a redox mediator to facilitate the electron transport originating from the bioactivity of cells. Several types of surface modification have been conducted, i.e., biocatalyst-mediator immobilisation and electropolymerisation of neutral red at the anode surface. The optimisation of each device has been characterised by cyclic voltammetry and chronoamperometry. It has also been observed in a microbial fuel cell (MFC), prior to being functioned in the MDC. The concentrations of salt ion migration have been determined by ion exchange chromatography. This study found that the best configuration of a modified surface was obtained from carbon felt coated by polyneutral red film (CF/PNR); this generated the maximum value of all tested parameters: $42.2 \%$ of current efficiency; $27.11 \%$ of bio-devices efficiency; $92.5 \mathrm{~mA} \mathrm{~m}^{-2}$ of current density; and $61 \%$ of $\mathrm{NaCl}$ transport. Moreover, the modified surface could be a promising method for improving anode performance.
\end{abstract}

Keywords: Seawater desalination, Microbial desalination cell, Surface modification, Microbial fuel cell, Green analytical chemistry

Article History: Received: $15^{\text {th }}$ November 2020; Revised: $25^{\text {th }}$ Dec 2020; Accepted: $10^{\text {th }}$ January 2021; Available online: $18^{\text {th }}$ January 2021

How to Cite This Article: Mardiana, U., Innocent, C., Cretin, M. and Buchari, B. (2021) A New Method of Bio-Catalytic Surface Modification for Microbial Desalination Cell. International Journal of Renewable Energy Development, 10(2), 345-354.

https://doi.org/10.14710/ijred.2021.34235

\section{Introduction}

As a newly-developed technology, a microbial desalination cell (MDC) is an electrical energy production system and is assimilated with a microbial fuel cell (MFC) and the electrodialysis process. Recently, environmental approaches and free energy requirements have resulted in MDC receiving extensive attention for wastewater treatment and desalination purposes. As an extension of its performance, MDC can be used as a stand-alone process or shared with other desalination processes, such as electrodialysis or reverse osmosis (RO) (Saeed, Yousef, \& Saif 2015). As mentioned previously, the MDC technology was an extension of an MFC, as shown in Fig. 1a. The MFC unit consists of an anode and a cathode, and each chamber is separated by a cation-selective membrane and an external wire. Meanwhile, the MDC unit (Fig. 1b) is adapted to the MFC; the presence of an anode and cathode chamber is necessary and a desalination chamber, known as the dilute and concentrate chamber, is added. The MDC configuration composes of the desalination chamber placed in the middle, designed by inserting the cation-exchange membrane (CEM) and anion-exchange membrane (AEM) on either side (Kim \& Logan 2013; Werner et al. 2013; Meng et al. 2014; Fane \& Wang 2017). The aerobic and anaerobic conditions are conserved in the anode and cathode chambers, respectively. In our last work, MFC-based Saccharomyces cerevisiae, also known as baker's yeast, was delivered and the electron transfer was facilitated by the presence of a mediator, as seen in Fig. 1a. Neutral red (NR) was selected as it is suitable as a redox mediator for the migration of electrons to the anode surface, which is probably due to the redox potential of $\mathrm{NADH} / \mathrm{NAD}^{+}$that was closer to redox potential of $\mathrm{NR}$ at $\mathrm{pH} 7$.

In our study, $\mathrm{pH} 7$ was applied as the $\mathrm{pH}$ of the anolyte because a high $\mathrm{pH}$ could affect the performance of yeast as a biocatalyst (Mardiana et al. 2015; Mardiana et al. 2019). Many different mediators have been studied previously, but only a few have reported on why several mediators work better than others (Babanova et al. 2011). However, the $\mathrm{pH}$ difference of an anodic solution influences the electron mediator's kinetics. Only then can the types of mediator be selected. Meanwhile, some biofuel cells can

\footnotetext{
*Corresponding author: ummy.mardiana@stikes-bth.ac.id
} 
operate using direct electron transfer, without the presence of a mediator. Here, the activity of microbes is due to the oxidisation of organic matter that realises protons and electrons (Champavert, Mardiana, \& Innocent 2017; Mulyono et al. 2020).

As already mentioned, in MDC construction, the anode is responsible for the organic degradation route and electricity generation. The cathode chamber, on the other hand, finalises the electrical loop. Meanwhile, the salt removal from seawater takes place in the middle chamber (Luo et al. 2012).

A basic MDC desalination process is illustrated in Fig. $1 \mathrm{~b}$. In the anode chamber, the organic process is carried out as a result of the behaviour of bacteria oxidising the organic matter. $\mathrm{CO}_{2}$ and proton are let loose into the anolyte, then the electron streams into the cathode through an external circuit, and current across the cell is recognised. Meanwhile, in the cathode chamber, the external electron acceptor and oxygen in the catholyte consumes these electrons in the reduction process and produces water (Mehanna et al. 2010; Qu et al. 2012). This causes a potential gradient in the anode and cathode chamber, in a direction that preserves electro-neutrality. Concurrently, the anion, such as the chloride ion, migrates from the dilute chamber (feed chamber) containing seawater, across the AEM, and into the concentrate chamber (receiving chamber), while the sodium ion flows across the CEM into the cathode chamber. This route is known as desalination and can eliminate more than $99 \%$ of the salt from saline water. At the same time, it harvests more energy and does not require an external energy supply because it can operate the system using its own energy (Forrestal et al. 2012; Meng et al. 2013; Zhang et al. 2016).

However, despite the abundant interest and growth in MDC technology, there are still some major challenges that must be addressed in the hopes of further expansion. The possibility of enhancing MDC performance should be explored and further exploited. Recently, MDC has advanced as a low-energy desalination technology. In the last century, the technology has been developed significantly due to its capability to sustainably provide freshwater through saltwater desalination. MDC has successfully shown that high salinity water can be desalinated without an energy supply. In addition, this method may also be simultaneously combined with waste water management and energy production (Jacobson, Drew, \& He 2011; Luo et al. 2012; Kim \& Logan 2013). During the desalination process, salt ions are removed from saline water through a conductive solution in the concentrate chamber; this increases the salinity in both the concentrate and cathode chambers. Meanwhile, the addition of ion is generally acceptable for wastewater treatment and supports the conditions required for conductivity (Luo et al. 2012; Wen et al. 2012).

As mentioned above, the application of MDC as a new approach for desalination has been conducted both in reactor designs and operational conditions. Several patterns of MDC, from two-chamber up-flow tubular to three-chamber or multi-chamber ones, have been investigated and included in the system's performance (Mehanna et al. 2010; Chen et al. 2011; Jacobson, Drew, \& He 2011; Kim \& Logan 2011). The MDC's performance can also be enhanced using multiple pairs of ion-exchange membranes (IEMs), placed between the anode and cathode chambers. This condition has been introduced on the grounds that the charge efficiency would improve and that the quantity of salt ion removed from saline water would significantly increase (Kokabian \& Gude 2015).

As reported before, the usage of Saccharomyces cerevisiae has been studied and the results have confirmed that it could affect MFC performance (Walker \& Walker 2006; Ganguli \& Dunn 2012; Sayed, Tsujiguchi, \& Nakagawa 2012), but the wider application of MDC needs to be further observed. In our work, the selection of yeast is motivated by the fact that some microorganisms, i.e., from the direct electron transfer group such as $G$. sulfurreducens and B. subtilis, have been observed in MDC (Mehanna et al. 2010; Kalleary et al. 2014). However, the use of yeast has never been demonstrated before. With this perspective in mind, and in order to improve electricity generation during the MDC process, the anode modification is designed. Three kinds of biocatalytic surface modifications are obtained through the biocatalyst-mediator immobilisation and electropolymerisation of NR on the surface of the anode.

The protocol surface modification refers to previous works (Mardiana et al. 2015; Mardiana et al. 2019). A study of biocatalyst immobilisation reported that such cells can have longer lifetimes than free cells, and can thus be a promising method for the enhancement of the biofuel cell's performance (Yong et al. 2013). Moreover, this situation can be adapted in MDC operation. Here, cell immobilisation refers to the technique delivered, such as physical entrapment within a porous matrix, encapsulation, or chemical cross-linking attachment (Taher et al. 2011).
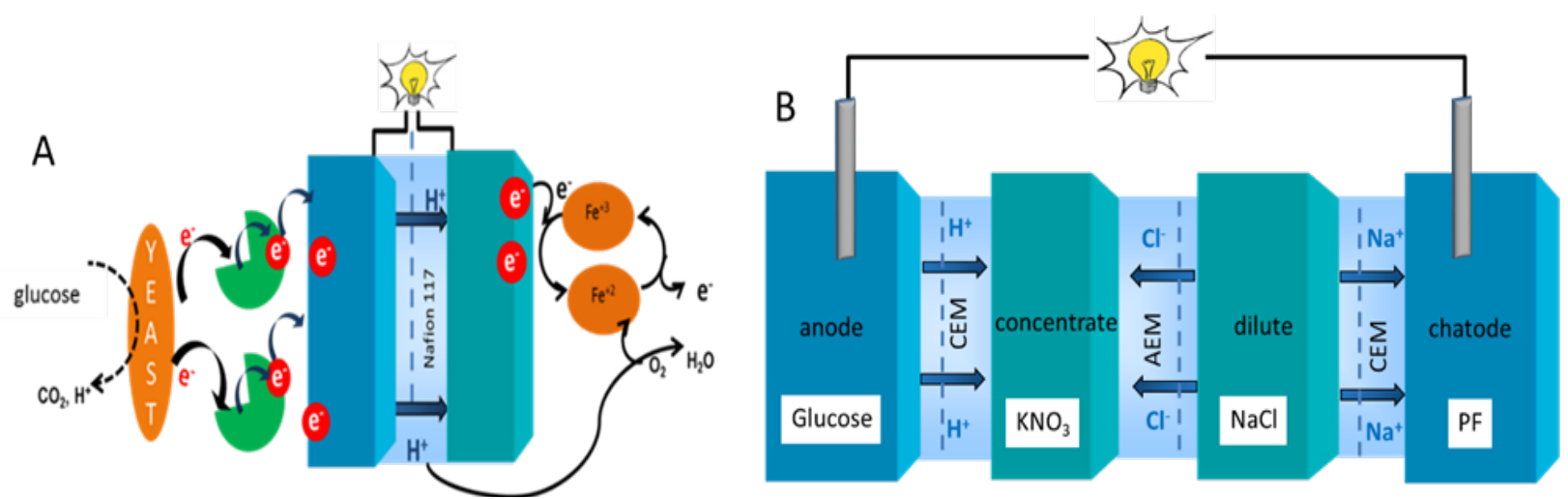

Fig. 1. Configuration design of: (a) MFC; (b) MDC. 
The principle of the immobilisation entrapped method is based on cell localisation within a polymer matrix or membrane. This method is commonly and preferably used in cell immobilisation. Several advantages have been obtained from this method, such as it being easy to operate, having a great loading capacity, and decreasing cell leakage (Cardona \& Sánchez 2007). In addition, this method can be applied in a wide variety of polymer materials, including synthetic and natural polymers. In our work, a natural polymer, i.e., calcium alginate, has been chosen because it is mostly used for cell immobilisation and has good stability (Cassidy, Lee, \& Trevors 1996; Maritz et al. 2003; Meena \& Raja 2006). One of the successful factors of immobilisation is the polymer support that must be conductive to allow the viability of the cell. It must also have a good permeability to permit oxygen transport, the supply of nutrients, and sufficient diffusion.

Nevertheless, applying physicochemical immobilisation between mediator and cell simultaneously can overcome the issue posed by the presence of a mediator in the solution, which can create an environmental problem if it is processed without proper treatment. Besides being used for sustainable green energy production, the enlargement of the operational system with the electron carrier powerfully immobilised at the bio-device is desirable. Meanwhile, poly-neutral red (PNR) has been synthesised and characterised electrochemically as a redox polymer to provide electron transfer in biosensors (Chen \& Lin 2001; Chen \& Gao 2007; Pauliukaite \& Brett 2008; Gonçalves, Ghica \& Brett 2011; Mardiana et al. 2015). The formation of PNR has been carried out following the electropolymerisation procedure, by allowing the monomer to oxidise for 20-30 cycles of polymerisation on the electrode material. The resulting film (PNR) plays the role of an electron carrier during MDC performance. Thus, challenges in designing costefficient MDC systems can be addressed by MFC experience-based anode modification.
Nowadays, the enlargement of MDC concept-based desalination that has been developed, but yeast deployment as a biocatalyst concurrently with surface modification is a new application. The yeast fuel cell poses an attractive potential as a low-cost desalination process with significant environmental profit. Therefore, the challenge to employ yeast and anode modification should be investigated further to enhance desalination performance and result in a significant salt ion migration. Previously, surface modification has focused on the development of anode modification. Herein, we demonstrate the potency of yeast and the effect of biocatalytic surface modification for the practical application of sustainable seawater desalination.

\section{Materials and Methods}

\subsection{Cell preparation}

A slurry of yeast is prepared, referring to the previous report (Sayed, Tsujiguchi, \& Nakagawa 2012), and cultivated at $30^{\circ} \mathrm{C}$ for 24 hours. It is composed of $2 \mathrm{~g}$ of dried yeast mixed with $1.8 \mathrm{~g}$ of peptone, $1.5 \mathrm{~g}$ of dextrose, and $1 \mathrm{~g}$ of malt extract (all the chemicals were obtained from Sigma-Aldrich, France). Then, they are dissolved in $50 \mathrm{~mL}$ of phosphate buffer (PB) with $\mathrm{pH}$ 7. The cells are centrifuged at $5000 \mathrm{rpm}$ for 5 minutes, harvested, and then washed twice in $\mathrm{PB} \mathrm{pH}$ 7. The re-suspended cells are conducted in $\mathrm{PB} \mathrm{pH} 7$. Prior to use, the cells are activated at $40^{\circ} \mathrm{C}$ for 5 minutes and stored at $4^{\circ} \mathrm{C}$.

\subsection{Bio-catalytic devices modification}

Carbon felt (CF) (Alfa-Caesar, United Kingdom), with dimensions $7 \times 1.5 \times 0.5 \mathrm{~cm}$, and nickel, $7 \times 1.5 \mathrm{~cm}$, are selected as the anode and cathode and are then connected externally by a copper wire. The electrodes are cleaned of trash material successively using $1 \mathrm{M} \mathrm{HCl}$ for 48 hours, and then rinsed with ultra-pure water.

A

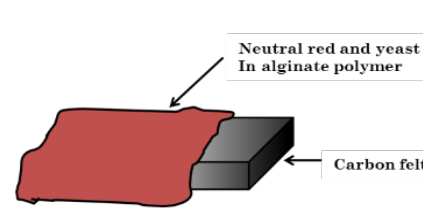

CF/Immob Y-NR

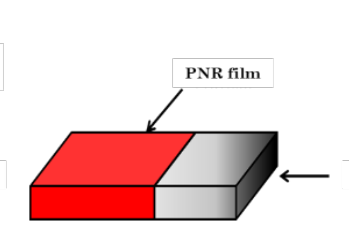

CF/PNR

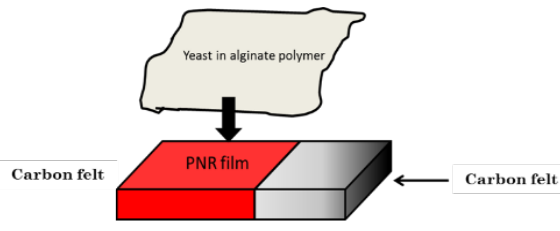

CF/PNR-Immob Y

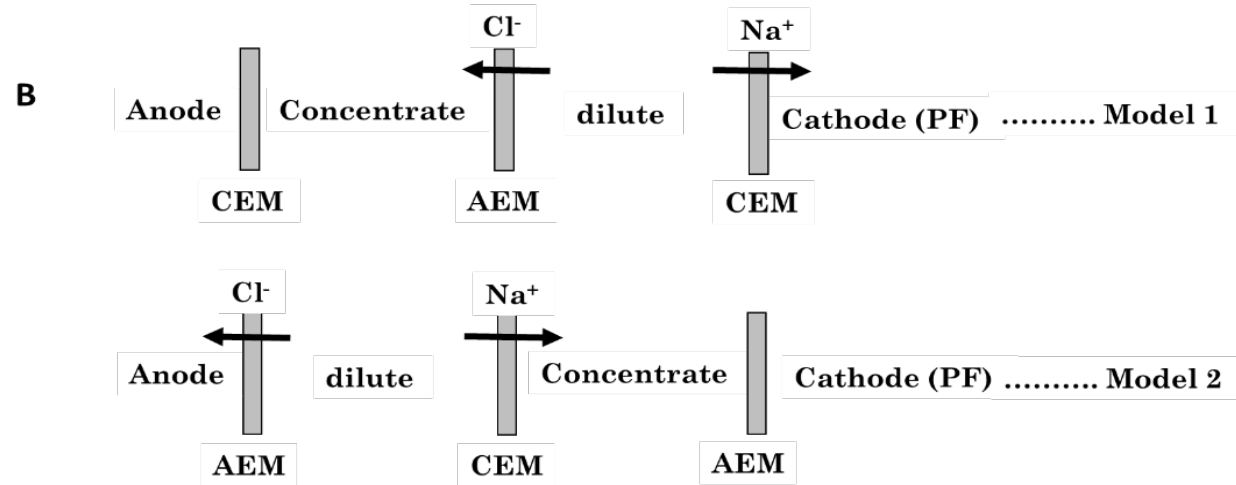

Fig. 2. The material and configuration modification: (a) Three kinds of bio-catalytic devices modifications; (b) Scheme configuration modification design of MDC. 
A mixture of 1:1 ethanol-water solution is used to soak the electrodes for a few minutes, followed by sonication in ultra-pure water. Subsequently, they are dried in the oven at $100^{\circ} \mathrm{C}$ for 15 minutes (Sayed, Tsujiguchi, \& Nakagawa 2012). Meanwhile, NR (Sigma-Aldrich, France) is selected as a redox mediator to facilitate electron transport to the anode.

A protocol of anode modification is adopted based on our previous studies, and Na-alginate (Sigma-Aldrich, France) is applied as a polymer matrix. Then, 2\% (w/v) yeast in $0.85 \%(\mathrm{w} / \mathrm{v}) \mathrm{NaCl}$ (Sigma-Aldrich, France) and 10 $\mathrm{mM}$ of $\mathrm{NR}$ is diluted in $\mathrm{PB} \mathrm{pH}$ 7. Meanwhile, Na-alginate is heated to $75-80^{\circ} \mathrm{C}$ for 30 minutes. After cooling slightly, the yeast solution and $\mathrm{Na}$-alginate are then mixed in the ratio of $1: 1$. The production of $\mathrm{CF} / \mathrm{Immobilisation}$ is obtained by immerging $\mathrm{CF}$ for 1 hour in the yeastalginate-NR solution, and then immerging for $1 \mathrm{~h}$ in 0.05 $\mathrm{M} \mathrm{CaCl}_{2}$ (Sigma-Aldrich, France), used as a reticulating agent (Mardiana et al. 2019). In the meantime, the formation of PNR takes place via cyclic voltammetry using the potentiostat VersaSTAT 3 (PAR AMETEK, United Kingdom), and the sweeping potential range is fixed from $-1.0-0.6 \mathrm{~V} / \mathrm{SCE}$ with a scan rate of $50 \mathrm{mV} / \mathrm{s}$ for 15 cycles. Platinum and a saturated calomel electrode (SCE) are chosen as the counter electrode (CE) and reference electrode (RE), respectively. The concentration of the NR solution is $10 \mathrm{mM}$ and it is dissolved in $0.025 \mathrm{M} \mathrm{PB} \mathrm{pH} 6$, and then 0.1 M KNO3 (Sigma Aldrich) is used as the electrolyte solution. The PNR characterisation is identified using a scanning electron microscope (SEM; Hitachi S-4800, Japan), energy dispersive x-ray spectroscopy (EDX) system (Hitachi S-4500, Japan), and UV-Vis spectrophotometer (Shimadzu, Japan) (Mardiana et al. 2015). All of the surface modifications are presented in Fig. 2a.

Three kinds of bio-catalytic surface modifications are deployed as anodes, and they successfully show excellent electrocatalytic activity and current generation. They are $\mathrm{CF} / \mathrm{Immob}$ yeast-NR (yeast-NR entrapped in Na-alginate immobilised on CF), CF/PNR (PNR polymerised on CF), and $\mathrm{CF} / \mathrm{PNR}$-Immob $\mathrm{Y}$ (PNR layer covered by yeast entrapped in Na-alginate, immobilised on $\mathrm{CF}$ ). The third surface is a combination of the first and the second surfaces of the modification method. The electrochemical characterisation is controlled using chronoamperometry and tested in $0.1 \mathrm{M}$ glucose (Sigma-Aldrich, France). A potential of $0.3 \mathrm{~V} / \mathrm{SCE}$ is used, where $\mathrm{CF}$ is modified as the working electrode (WE), SCE as a RE, and platinum as a CE.

\subsection{Biofuel cell construction and process}

MFC and MDC chambers are designed as presented in Figs $1 \mathrm{a}$ and $1 \mathrm{~b}$. The MFC compartment consists of anode and cathode chambers, while the MDC compartment is composed of the anode, concentrate, dilute, and cathode chambers. Here, CEM is placed next to the anode and is followed by the AEM, separating the concentrate and dilute chambers. The CEM is then located close to the cathode chamber. Each chamber has a volume capacity of $80 \mathrm{~mL}$. As membranes, the CEM and AEM are prepared using CMX (CMI-7000) and AMX-SB (AMI-7001) (Tokuyama Soda- Japan) and the diameter size of the membrane is $3 \mathrm{~cm}$. The carbon source in the anode chamber is $0.1 \mathrm{M}$ glucose in $\mathrm{PB} \mathrm{pH} 7$, while $0.5 \mathrm{M} \mathrm{KNO}_{3}$ (Sigma-Aldrich, France) is placed in the concentrate chamber, and the dilute chamber is filled with seawater. In the cathode chamber, $0.02 \mathrm{M} \mathrm{K}_{3} \mathrm{Fe}(\mathrm{CN})_{6}(\mathrm{PF})$ (Sigma Aldrich France) acts as an electron acceptor, and this solution has been diluted in $\mathrm{PB} \mathrm{pH}$ 7. Prior to use, all membranes are soaked in $0.1 \mathrm{M} \mathrm{HNO}_{3}$ for 1 hour and then washed with ultra-pure water. All of the bio-catalytic surface modifications are applied as an anode, while the nickel plate acts as a cathode.

Fig. 2b explains the scheme design of the modified MDC. This section aims to observe the best configuration for MDC design. First, the MDC experimental is set up to refer to model 1, but herein, the arrangement of the concentrate and dilute chamber location has been changed and renamed model 2. The composition of the solutions consists of $0.1 \mathrm{M} \mathrm{KNO}_{3}$ and $0.1 \mathrm{M} \mathrm{NaCl}$ in the concentrate and dilute chambers, respectively.

All desalination takes place at ambient temperature $\left(25 \pm 1^{\circ} \mathrm{C}\right)$. In order to investigate the influence of external resistance on the performance of MDCs, the external resistance varies in the range of $100 \Omega-3 \mathrm{k} \Omega$ using a resistance box. A digital multimeter voltcraft model VC 850 (Germany) is employed to investigate the potential (E) generated and the current is calculated according to the equation $\mathrm{I}=\mathrm{E} / \mathrm{R}$. The monitoring of salt ion removal from the dilute and concentrate chambers is measured using ion-exchange chromatography (Dionex ICS-900 for the cation and Dionex ICS-1000 for the anion). Meanwhile, the percentage of salt ion removal is calculated using Eq. 1 :

$$
\% \text { transport }=\frac{[C] t}{[C o]} \times 100 \%
$$

$C$ and $C o$ are measures of concentration in $\mathrm{mg} / \mathrm{L}$, where $C$ is ion concentration at the time of measurement and $C o$ is the initial concentration.

The current efficiency obtained from the modified surface is measured using Eq. 2 (Heidrich, Curtis, \& Dolfing 2011):

$$
\eta_{\mathrm{i}}=\frac{F \cdot z \cdot V \cdot \Delta c}{N c p \cdot \int i d t}
$$

The efficiency of the modified anode is calculated from the value of current efficiency (ni) generated during the MDC demonstration. The current efficiency is the number of ions divided by the number of electrons transferred at the bio-device's modification, where $\Delta c$ is the reduction of saltwater concentration, $V$ is the volume desalinated, $N c p$ is the number of cell pairs, and $i$ is the current. We can then estimate the amount of PNR deposited on the surface by referring to Eq. 3:

$$
\text { b.w.F/M }=\int_{0}^{t} I d t / v
$$

Here, $b$ is the number of electrons exchanged per mole involved in the redox couple of PNR $(b=2)$, w $(\mathrm{g})$ is the weight of PNR, F is the Faraday constant $\left(96.500 \mathrm{Cmol}^{-1}\right)$, $\mathrm{M}$ is NR molecular weight, and $v$ represents the scan rate. 

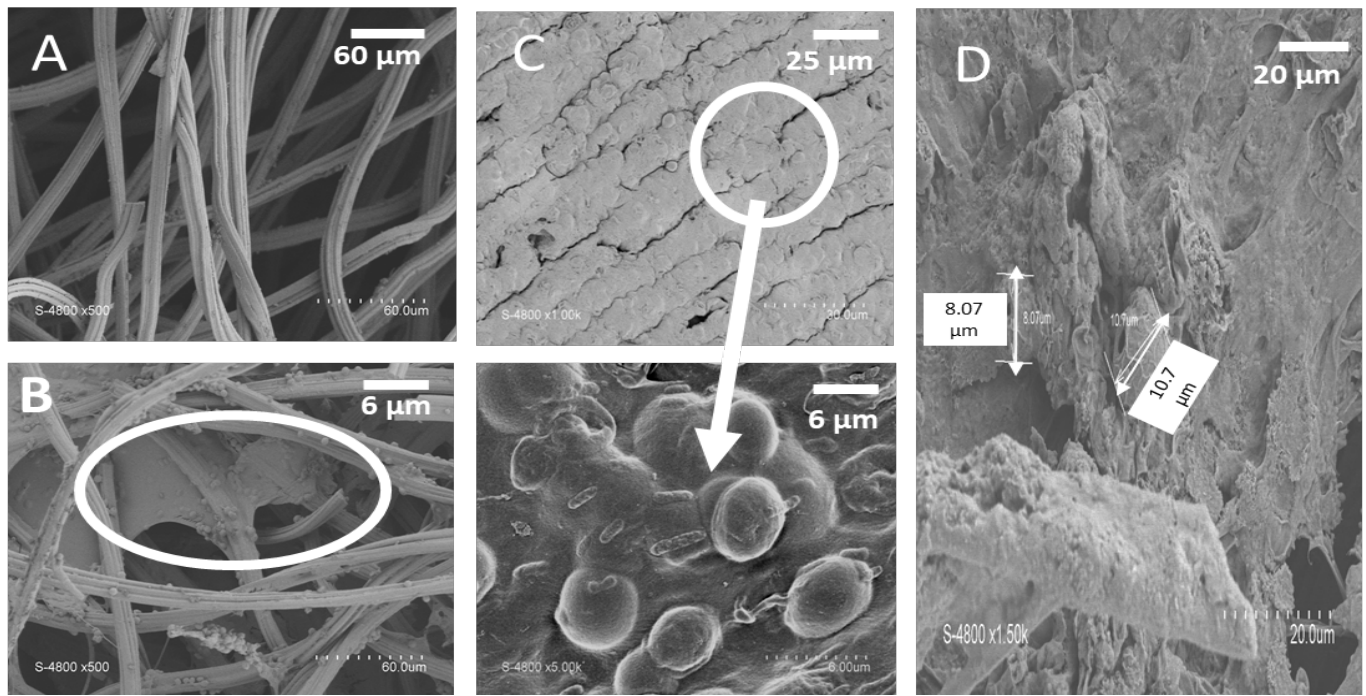

Fig. 3. SEM images of anode: (a) CF; (b) CF/PNR; (c) CF/Immob Yeast-NR; (d) CF/PNR-Immob Yeast.

\section{Results and Discussion}

\subsection{The bio-catalytic devices modification characterisation and its electrocatalytic activities}

The surface images of anode modification by immobilisation of yeast within the alginate polymer and PNR layer on the anode surface were observed by SEM, as displayed in Fig. 3. Images revealed that there were several spherical shapes around $4 \mathrm{~nm}$, spread homogenously within the alginate polymer film and confirmed to be yeast cells. The thickness of the alginate polymer film varied from 4 to $16 \mathrm{~nm}$ and had a good roughness due to the presence of yeast inside, ready to be used for the electro-catalytic process. Meanwhile, the characterisations of PNR formation were identified using EDX images and UV-Vis spectroscopy. The results are shown in Fig. 4.

Figs $4 \mathrm{a}$ and $4 \mathrm{~b}$ show the morphology of the PNR film deposited on the $\mathrm{CF}$ support, referring to the EDX spectrum. The results found that $5.04 \%$ of $\mathrm{N}$ were contained in the CF-modified surface and it was confirmed that the PNR had been present on the CF surface. The presence of $\mathrm{C}$ and $\mathrm{N}$ atoms was expected since they came from NR and CF. The potassium and oxygen atoms from the $\mathrm{KNO}_{3}$ solution, which was used as the supported electrolyte solution during the synthesis of polymer, and sodium could be delivered from the phosphate buffer as the supporting $\mathrm{pH}$ solution. Meanwhile, Fig. 4c shows that the first peak appeared at $268 \mathrm{~nm}$ which corresponded to the oxidation of monomer produces 5.10 dihydrogen neutral red (Eq. 4; Yang et al. 2006) and the same profile curve also appeared at $532 \mathrm{~nm}$. The broad and very weak band could be due to the chain of PNR that was longer than that of the monomer. The differential band between NR and PNR implied that, after electrolysis, neutral red was actually polymerised. As a preliminary step, the observation of current density of bio-devices modification was recorded using chronoamperometry before it was applied in MDC. All of the experiment results can be seen in Fig. 5.
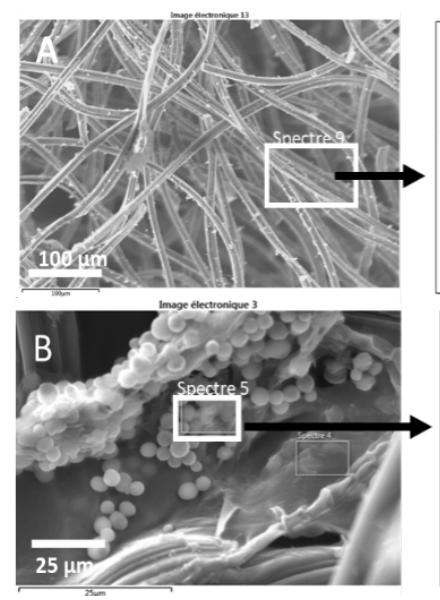
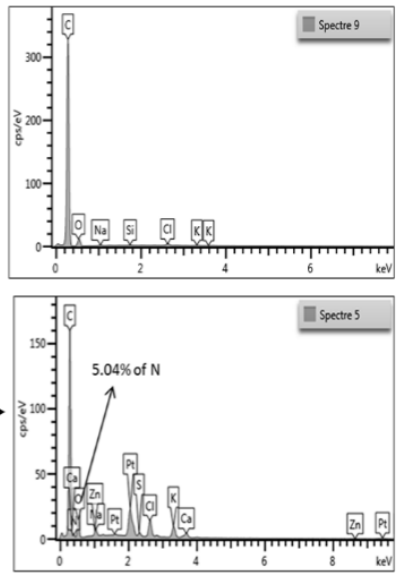

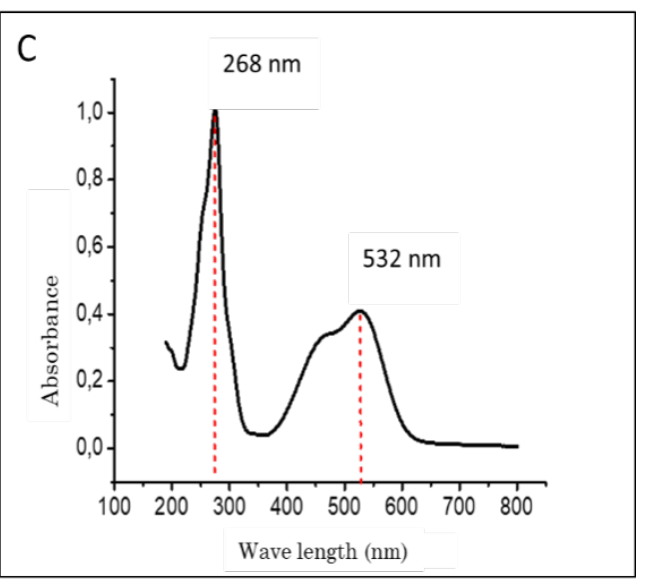

Fig. 4. PNR characterisation observed by EDX and UV-Vis spectra; (a) EDX images of CF; (b) EDX images of CF/PNR after being applied in MDC; (c) UV-Vis spectrum of PNR. 

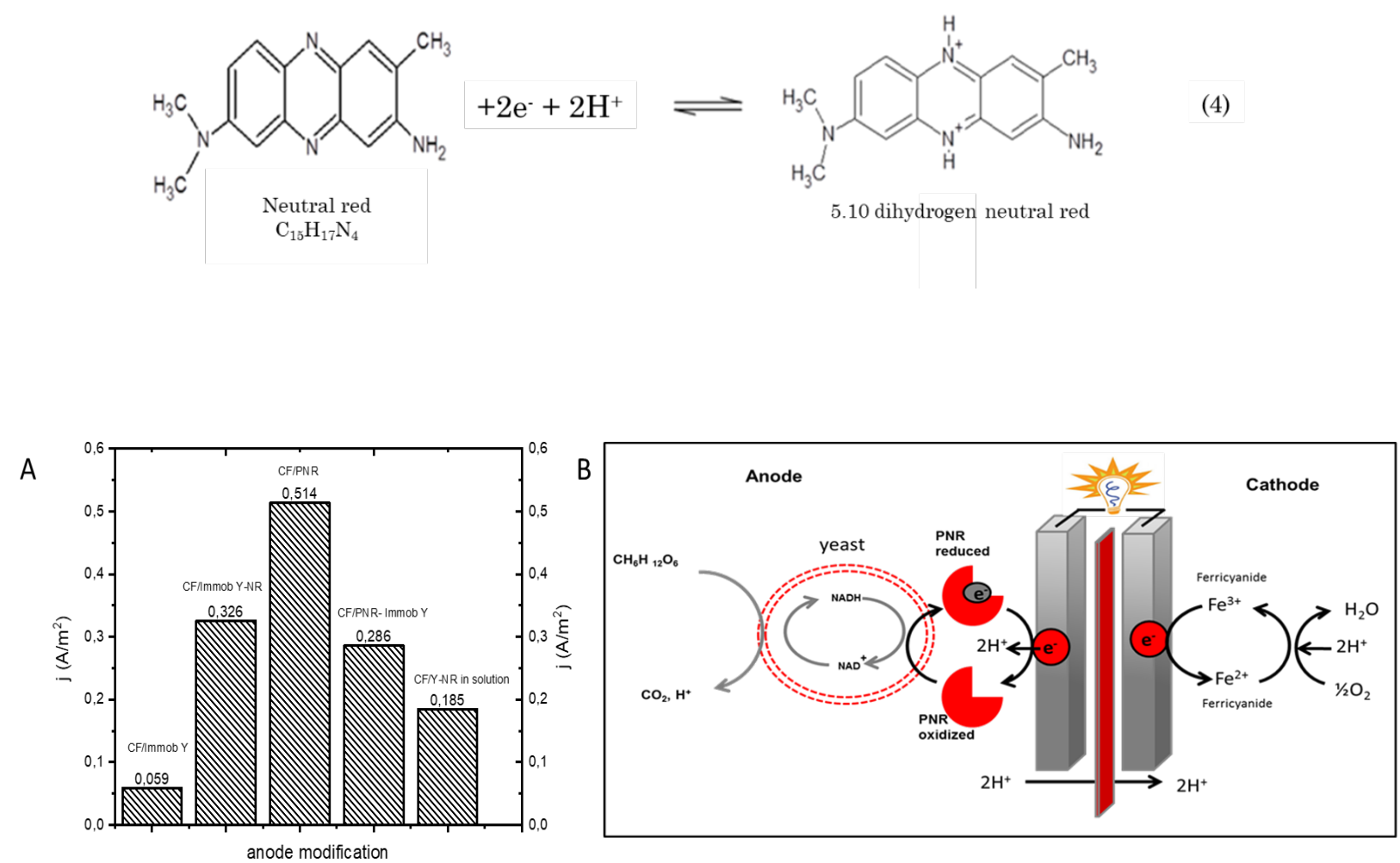

Fig. 5. (a) Current density generated from all electrode modifications in $0.1 \mathrm{M}$ glucose solution, observed by chronoamperometry; (b) The scheme of electron transfer facilitated by PNR during anaerobic fermentation pathway of yeast.

The chronoamperometry observation was performed and electrodes were polarised at $0.3 \mathrm{~V} / \mathrm{SCE}$ to ensure glucose oxidation. All surface modifications were tested as working electrodes and $\mathrm{Pt}$ was tested as a counter electrode. The results reported that $\mathrm{CF} / \mathrm{PNR}$ delivered the highest current density compared to others. Meanwhile, $\mathrm{CF}$ without modification was examined as well, using $2 \%$ of yeast and $10 \mathrm{mM} \mathrm{NR}$ in $\mathrm{PB} \mathrm{pH} 7$ solution. Fig. 5a reports that the PNR layer gave the best performance and generated $64 \%$ of current density value against the conventional method, i.e., CF/Y-NR in solution. Meanwhile, CF/Immob Y-NR and CF/PNR-Immob produced $43 \%$ and $35 \%$ of current density values, respectively, compared with those a non-modified surface. Meanwhile, electrochemical response from CF/Immob-Y without involving NR was fixed as the baseline of measurement. All the current density values generated were monitored for 2 hours after 30 minutes of stabilisation time.

In the next step, all of the modified anodes have been employed in MFC before working in MDC. The purpose of this section is to observe the biocatalyst activity which is facilitated by the mediator on the anode surface. MFC working with surface modification shows a good stability of current; thus, the best conditions have resulted from CF/PNR. The scheme of electron transfers from glucose to the electrode has been explained in Fig. 5b. The PNR oxidised form captures electrons generated and PNR reduced form directly transfers electrons to the anode. The recycling of $\mathrm{NADH}$ to $\mathrm{NAD}^{+}$is important as it sustains the glycolysis process in fermentation pathways. The use of redox mediators, substituting the space between the oxidised state (PNRox) and reduced state (PNRred), is obligatory to touch the electron transfer chain, which is found at the mitochondria within the cytoplasm (Chen \& Lin 2001).

\subsection{Microbial desalination cell characterisation}

First, the selection of resistance is observed in MDC where $\mathrm{CF} / \mathrm{PNR}$ is chosen as the anode. Voltages were recorded and monitored using a multimeter voltcraft (model VC 850). To test the fuel cell under different loads, the cell was connected to a decade resistance box and the potential difference across the load was recorded from 100 $\Omega$ to $3 \mathrm{k} \Omega$. The values were recorded for $5-10$ minutes until the voltage is stabilised. After being calculated, the maximum power density was found at $1 \mathrm{k} \Omega$ resistance and thereafter, this external resistor was used in all subsequent experiments. As preliminary work, the selection of the best MDC configuration was done using a non-modified surface. The composition of the anode chamber in the MDC consists of $2 \%$ yeast, $10 \mathrm{mM} \mathrm{NR}$, and $0.1 \mathrm{M}$ glucose in $\mathrm{PB} \mathrm{pH}$ 7. Meanwhile, the concentrate and dilute chambers are filled with $0.1 \mathrm{M} \mathrm{KNO}_{3}$ and $0.1 \mathrm{M}$ $\mathrm{NaCl}$, respectively, and the cathode contains $0.02 \mathrm{M} \mathrm{PF}$. The observation of current density was recorded for 10 days, delivered from each variation of the MDC design, and the results can be seen in Fig. 6a. 
A

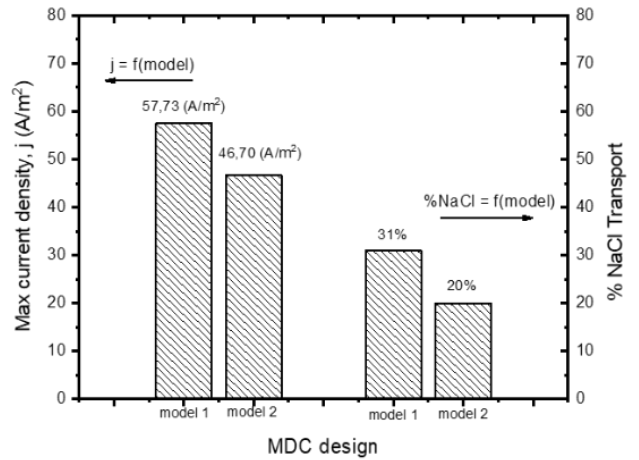

B

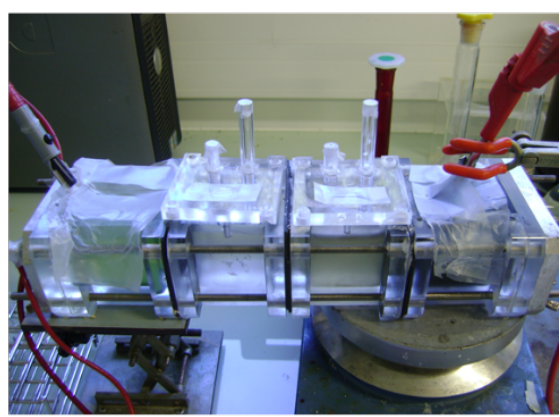

Fig. 6. (a) Current density and \% of $\mathrm{NaCl}$ transport produced from variation of MDC designs; (b) A photograph of the MDC reactor.
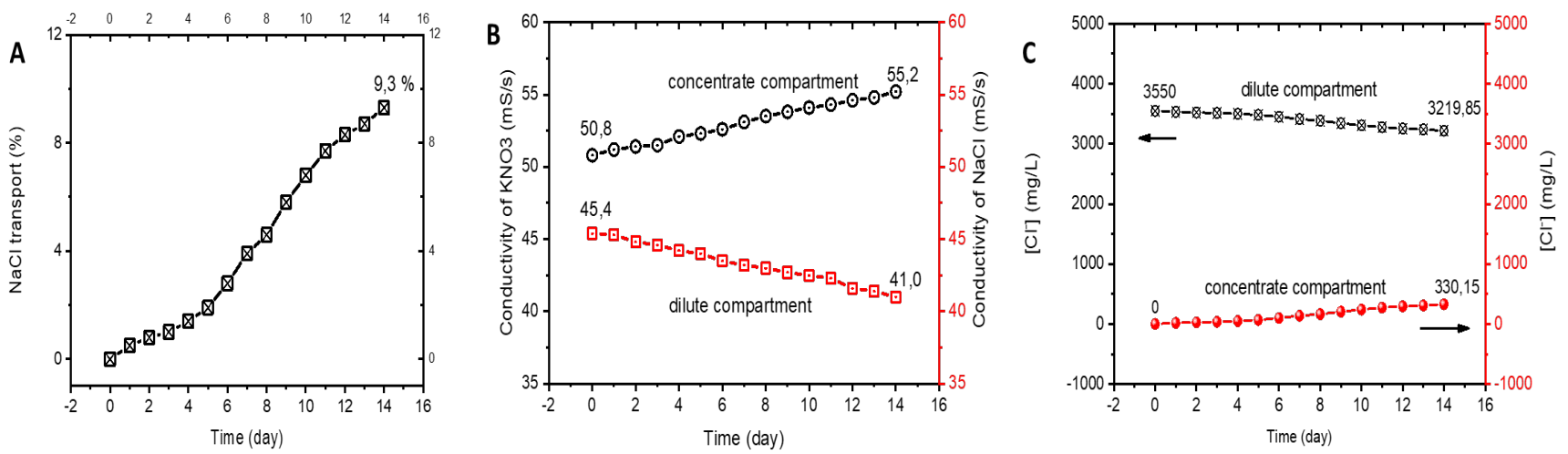

Fig. 7. The MDC characterisation: (a) \% of $\mathrm{NaCl}$ transport generated from diffusion process; (b) Conductivity value of dilute and concentrate chambers generated from diffusion process; (c) The concentration of $\mathrm{Cl}$ - ion delivered from the electrodialysis process.

Fig. 6a illustrates that the \% of salt ion transport of model 2 was lower than that of model 1 . In model $1,31 \%$ of salt ions successfully migrated from the dilute to the concentrate chamber, while $20 \%$ of the $\mathrm{NaCl}$ was removed from the initial concentration. The $\mathrm{Cl}$ ion migrated from the dilute chamber to the anode and passed through the AEM. In contrast, the $\mathrm{Na}^{+}$ion moved to the concentrate chamber after passing through the CEM. Moreover, the $\mathrm{pH}$ measurement of the anolyte was investigated, and the results obtained revealed that the $\mathrm{pH}$ decreased from 6.88 to 4.78. It was assumed that protons could not pass through the AEM membrane, so they remained in the anode chamber. At the same time, the presence of $\mathrm{Cl}$ - ion would react with protons and produce $\mathrm{HCl}$. The evolution of the anolyte's pH value could affect the stability of the biocatalyst's performance. Based on this, model 2 is no longer recommended to be used in the next MDC demonstration.

Characterisation of MDC was then followed by the observations of the diffusion process where the concentration gradient across the IEM could also induce ion diffusion processes. In our study, this phenomenon was monitored using model 1 of the MDC for 14 days of operation, and without the presence of yeast in the anode. The results are displayed in Fig. 7.
Results confirm that $9.3 \%$ of the $\mathrm{Cl}^{-}$ion concentration was reduced from the dilution compartment (Fig. 7a). This can be interpreted as the diffusion contributing to the MDC process. Meanwhile, the observation of conductivity from the MDC has carried out. With reference to concentration chamber, the conductivity value increased by $9 \%$, from the initial $50.8 \mathrm{mS} / \mathrm{s}$ to $55.2 \mathrm{mS} / \mathrm{s}$ (Fig. 7b). The concentration gradient across the IEM also induced osmotic water transport. This suggests that the transport of osmotic water was delivered from the cathode and concentrate chambers to the dilute chamber. During the diffusion process, $8.4 \mathrm{~mL}$ of water moved into the dilute chamber over the 14 days of MDC performance, and it resulted in a reduction of salinity of up to $9.3 \%$ (from the initial $3.5 \mathrm{~g} / \mathrm{L} \mathrm{NaCl}$ ). Concurrently, the electrodialysis process was monitored using chronopotentiometry by the employing a current of $50 \mu \mathrm{A}$, which refers to the average value of the current generated from model 1. Fig. 7c. reports that the $\mathrm{Cl}$ - ions migrated from the dilute to the concentrate chamber during electrodialysis, and resulted in $16 \%$ of ion transport over the 14 days of the electrodialysis process. However, it should be noted that the most important driving force in the MDC is the electric current generated by exoelectrogenic microbes. 

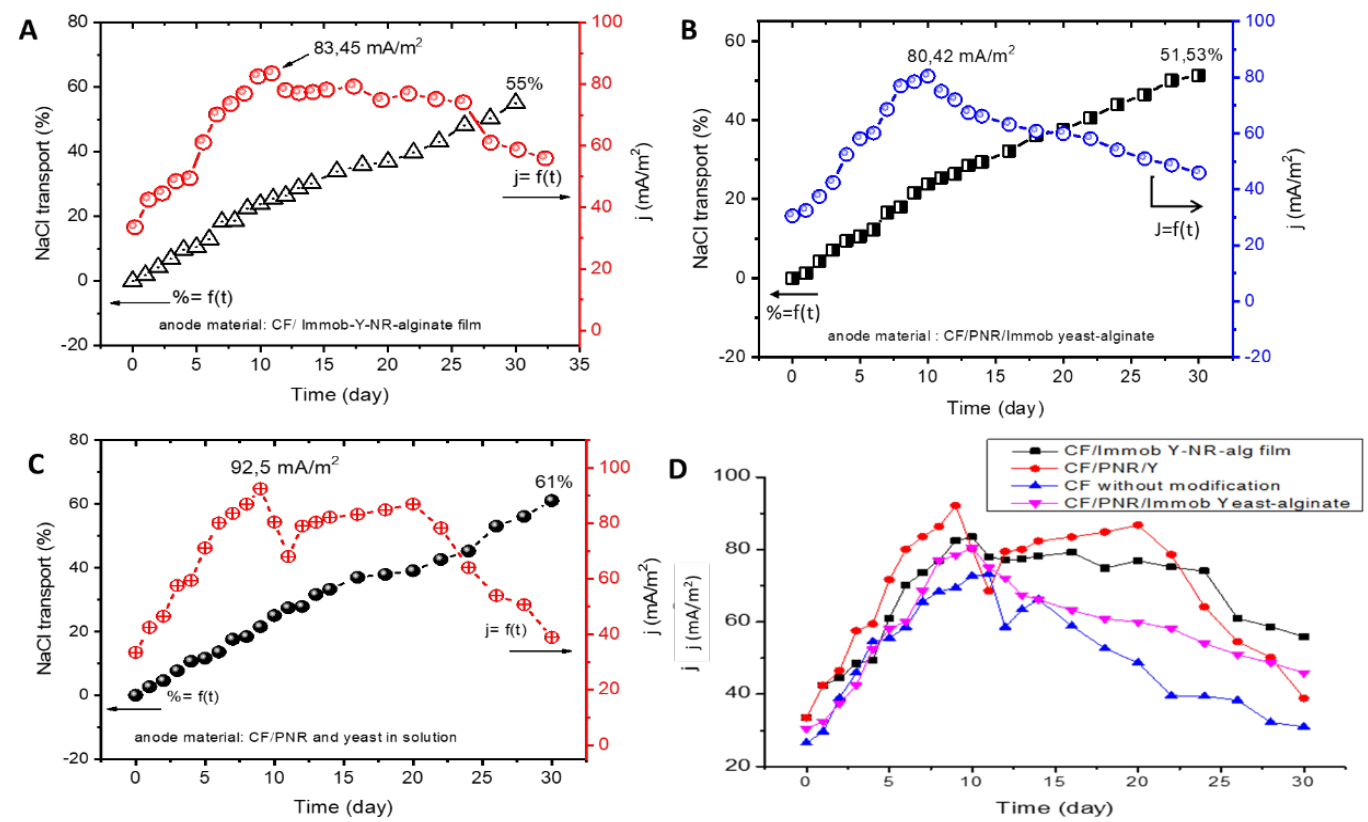

Fig. 8. The evolution of current density and \% of $\mathrm{NaCl}$ transport generated from MDC using bio-devices modification: (a) CF/Immob YNR; (b) CF/PNR-Immob Y; (c) CF/PNR; (d) Summary of all MDC experiment parts.

\subsection{Microbial desalination cell using bio-devices modification.}

The first MDC observation was made by employing a nonmodified CF. The composition of the anode chamber consists of $2 \%$ yeast, $10 \mathrm{mM} \mathrm{NR}$, and $0.1 \mathrm{M}$ glucose in $\mathrm{PB}$ $\mathrm{pH}$ 7. Meanwhile, the concentration and dilution chambers are filled by $0.1 \mathrm{M} \mathrm{KNO}_{3}$ and $0.1 \mathrm{M} \mathrm{NaCl}$, then the cathode is packed by $0.02 \mathrm{M}$ PF. Results show that $43 \%$ of $\mathrm{NaCl}$ transport and $73.3 \mathrm{~mA} / \mathrm{m}^{2}$ of maximum current density were obtained from MDC over 30 days. The observation of salt ion concentration was measured from the dilution chamber. The maintenance of the MDC was carried out every $13^{\text {th }}$ day, with the addition of $1 \mathrm{~g}$ of glucose at the anode and substitution of the PF solution at the cathode. As seen in Fig. 8d, initially, the currents generated increased, and then they gradually decreased until the $13^{\text {th }}$ day. However, after refreshing the anolyte and catholyte solutions, an improvement of the current value did not appear until at the end of the performance period. Thus, it can be assumed that the stability of yeast is limited.

Hereinafter, further experiment was performed by varying the modified bio-catalytic surface as the anode in the MDC's performance. First, CF/Immob Y-NR was tested in MDC and resulted in a maximum current density of $83 \mathrm{~mA} / \mathrm{m}^{2}$ and $55 \% \mathrm{NaCl}$ transport. Fig. 8a describes that on the $11^{\text {th }}$ day, the current began to reduce slightly, and that from the 20th day, there was a decline until the end of the process.

The second modification is CF/PNR-Immob Y and the bio-catalytic activity recorded in the MDC is displayed in Fig. $8 \mathrm{~b}$. The maximum current density and percentage of $\mathrm{NaCl}$ transport was $80.2 \mathrm{~mA} / \mathrm{m}^{2}$ and $51.53 \%$, respectively. After the $11^{\text {th }}$ day, although glucose and $\mathrm{PF}$ had been added, it seemed that there was no significant effect on the signal produced. On the modified surface created by the immobilisation formation of the cell-mediator within the alginate layer, whether it was produced by CF/Immob YNR or CF/PNR-Immob Y, the thickness of the layer should be considered. However, in addition to the alginate layer's thickness, the presence of the alginate layer and the complete availability of PNR is believed to be contribute towards this situation. It may also be due to one of the barriers of glucose to the entry into the layer surface, where the electricity produced depends mostly on glucose oxidation. The results showed a slight decrease in the current produced before the achievement of the MDC, although explanations for the same need to be further explored.

Referring to our previous work (Mardiana et al. 2019), normally, the electrochemical signal would increase in line with the addition of glucose in the anode chamber and the $\mathrm{PF}$ replacement in the cathode chamber. This situation can affect the uptime of biofuel performance. Additionally, the stability of yeast was also found to be limited and it was generally proven that there was no significant effect on the current generated, although the system had been maintained.

The last modification is the formation of $\mathrm{CF} / \mathrm{PNR}$. The electro-signal actions were investigated and provided a maximum current density of $92.5 \mathrm{~mA} / \mathrm{m}^{2}$ and $61 \% \mathrm{NaCl}$ transport (Fig. 8c). Compared with the others, this value is the highest for both current density and percentage of $\mathrm{NaCl}$ transport. On the 12th day, the reduction of the electrochemical signal occurred and slightly dropped from the 19th day, until the MDC had finished. It was suggested that the presence of the PNR layer was successful in serving as a redox mediator and providing efficient electron transport. All of the MDC experiments resulted from the effect of modified surface can be seen in Fig. 8d. 
Table 1

Current efficiency, bio-devices efficiency, and flux delivered from MDC.

\begin{tabular}{cl|lccc}
\hline No & Bio-device modification & \multicolumn{1}{c}{ Composition of anode chamber } & $\begin{array}{c}\text { Current } \\
\text { efficiency }\left(\eta_{\mathrm{i}}\right)\end{array}$ & $\begin{array}{c}\text { Amount of } \\
\text { mediator }(\mu \mathrm{g})\end{array}$ & $\begin{array}{c}\text { Bio-devices } \\
\text { efficiency }\left(\mathrm{\eta}_{\mathrm{i}}\right) / \mathrm{g}\end{array}$ \\
\hline 1 & CF/PNR & Yeast 2\%; 0.1 M glucose/PB pH 7 & $42.2 \%$ & $14.2 \mu \mathrm{g}$ & 27.11 \\
2 & CF/Immob Y-NR & $0.1 \mathrm{M}$ glucose/PB pH 7 & $38.5 \%$ & $0.029 \mathrm{~g}$ & 22.84 \\
3 & CF/PNR-Immob Y & 0.1 glucose/PB pH 7 & $36.1 \%$ & $15.8 \mu \mathrm{g}$ & 15.55 \\
4 & Non-modified CF & $\begin{array}{l}\text { Yeast 2\%; NR 5 mM and 0.1 M } \\
\text { Glucose/PB pH 7 }\end{array}$ & $29.3 \%$ & $1.599 \mathrm{~g}$ & 0.18 \\
\hline
\end{tabular}

The formation of PNR has given the best results compared with NR entrapped within alginate immobilisation. Thus, PNR was relatively stable on the anode surface. However, the modified anode technique using PNR formation on the surface should be improved and further exploited in order to minimise the amount of PNR penetration into the anode solution. The value of current efficiency and the bio-device's efficiency from all the modified anodes was calculated using Eq. 2 and Eq. 3 . The results can be seen in Table 1 .

The highest value of current efficiency and bio-device efficiency is provided by CF/PNR. The current efficiency depends on the presence of a mediator in the anolyte, since the mediator has allowed the transport of electrons. Meanwhile, the efficiency of the modified bio-devices is expressed by the mass of mediators accessible from each bio-device. Table 1 shows that CF/PNR has the highest efficiency value, followed by CF/Immob Y-NR and CF/PNR-Immob Y. The manifestation of the PNR layer at the anode surface was thought to be more efficient than on the monomer (NR) trapped in the yeast immobilisation layer. According to Eq. 3, we can estimate the quantity of PNR on the modified surface as 14.2 $\mu \mathrm{g} / \mathrm{cm}^{2}$ from $10.2 \mathrm{~cm}^{2}$ of surface area.

In addition, the composition of seawater had been determined before use and a large concentration of sodium and chloride was derived (i.e., $12.14 \mathrm{~g} / \mathrm{L}$ and $22.85 \mathrm{~g} / \mathrm{L})$. Meanwhile, the following ions were also obtained: nitrate $(1.35 \mathrm{~g} / \mathrm{L})$; nitrite $(0.99 \mathrm{~g} / \mathrm{L})$; sulphate $(6.30 \mathrm{~g} / \mathrm{L})$; potassium $(2.05 \mathrm{~g} / \mathrm{L})$; calcium $(3.05 \mathrm{~g} / \mathrm{L})$; magnesium $(2.05 \mathrm{~g} / \mathrm{L})$; and phosphate $(0.98 \mathrm{~g} / \mathrm{L})$. During the MDC progression, the electrical potential gradient was created by the electrode reactions, and was commonly responsible for salt ion migration. Furthermore, the IEM junction potential and water transport may have also affected the desalination rate. In a four-chamber MDC, these factors may play the role of additional driving forces for desalination.

\section{Conclusion}

Many challenges in designing cost-efficient MDC systems have been demonstrated by employing modified bio-catalytic surfaces as an anode in an MDC. We have presented a method of bio-catalytic surface modification with a simple construction and design. The results show that highly significant performance by $\mathrm{CF} / \mathrm{PNR}$ and the maximum values obtained were $42.2 \%\left(\eta_{\mathrm{i}}\right)$ of current efficiency, 27.11( $\left.\mathrm{n}_{\mathrm{i}} \mathrm{i} / \mathrm{g}\right)$ of bio-devices efficiency, 95.2 $\mathrm{mA} / \mathrm{m}^{2}$ of current density, and $61 \%$ of $\mathrm{NaCl}$ transport.
Therefore, the findings demonstrated in this present study are greatly substantial as much can be learnt from it and can be applied in future challenges in industry application.

\section{Acknowledgments}

The author gratefully acknowledges the financial support received from National Research and Innovation Agency, Ministry of Research and Technology of the Republic of Indonesia, in terms of the Basic Research Grant and the partial support received from European Membrane Institute, Montpellier, France.

\section{References}

Babanova S., Hubenova Y., and Mitov M. (2011). Influence of artificial mediators on yeast-based fuel cell performance. Journal of Bioscience and Bioengineering, 112, 379-387. DOI:10.1016/j.jbiosc.2011.06.008.

Cardona C.A., and Sánchez O.J. (2007). Fuel ethanol production: process design trends and integration opportunities. Bioresource Technology, 98, 2415-2457. DOI: 10.1016/j.biortech.2007.

Cassidy M.B., Lee H., and Trevors J.T. (1996). Environmental applications of immobilized microbial cells: A review. Journal of Industrial Microbiology, 16, 79-101. DOI: 10.1007/BF01570068.

Champavert J., Mardiana U., and Innocent C. (2017). Biocatalytic Devices for Energy Production. Current Organic Chemistry, 21, 1702-1712. DOI: $10.2174 / 1385272821666170427155324$.

Chen C., and Gao Y. (2007). Electrosyntheses of poly(neutral red), a polyaniline derivative. Electrochimica Acta, 52, 3143-3148. DOI 10.1016/j.electacta.2006.09.056

Chen S.M., and Lin K.C. (2001). The electrocatalytic properties of polymerized neutral red film modified electrodes. Journal of Electroanalytical Chemistry, 511,101-114. DOI: 10.1016/S0022-0728(01)00566-6.

Chen X., Xia X., Liang P., Cao X., Sun H., and Huang X. (2011). Stacked Microbial Desalination Cells to enhance water desalination efficiency. Environmental Science and Technology, 45, 2465-2470. DOI: 10.1021/es103406m .

Fane A.G., and Wang R. (2017). Bioinspired Membrane Engineering for Water Applications : Examples of enhanced membranes, mass transfer and biofilm control. Current Organic Chemistry, 21,1665-1670. DOI: 10.2174/1385272820666160608124841.

Forrestal C., Xu P., Jenkins P.E., and Ren Z. (2012). Microbial desalination cell with capacitive adsorption for ion migration control. Bioresource Technology, 120, 332-336. DOI: 10.1016/j.biortech.2012.06.044. 
Ganguli R., and Dunn B. (2012). Electrically conductive, immobilized bioanodes for microbial fuel cells. Nanotechnology, 23, 1-7. DOI: $\quad 10.1088 / 0957-$ $4484 / 23 / 29 / 294013$.

Gonçalves R., Ghica M.E., and Brett C.M.A. (2011). Preparation and characterisation of poly(3,4-ethylenedioxythiophene) and poly(3,4-ethylenedioxythiophene)/poly(neutral red) modified carbon film electrodes, and application as sensors for hydrogen peroxide. Electrochimica. Acta, 56, 3685-3692. DOI: 10.1016/j.electacta.2010.11.056.

Heidrich E.S., Curtis T.P., and Dolfing J. (2011). Determination of the internal chemical energy of wastewater. Environmental Science and Technology, 45, 827-832. DOI: 10.1021/es103058w.

Jacobson K.S., Drew D.M., and He Z. (2011). Efficient salt removal in a continuously operated upflow microbial desalination cell with an air cathode. Bioresource Technology, 102, 376-380. DOI: 10.1016/j.biortech.2010.06.030

Kalleary S., Abbas M.F., Ganesan A., Meenatchisundaram S., Srinivasan B., Packirisamy B.S.A., Kesavan K.R., and Muthusamy S. (2014). Biodegradation and bioelectricity generation by Microbial Desalination Cell. International Biodeterioration \& Biodegradation, 92, 20-25. DOI: 10.1016/j.ibiod.2014.04.002.

Kim Y., and Logan B.E. (2011). Series assembly of Microbial Desalination Cells containing stacked electrodialysis cells for partial or complete seawater desalination. Environmental Science and Technology, 45, 5840-5845. DOI: 10.1021/es200584q.

Kim Y., and Logan B.E. (2013). Simultaneous removal of organic matter and salt ions from saline wastewater in bioelectrochemical systems. Desalination, 308, 115-121. DOI: 10.1016/j.desal.2012.07.031.

Kokabian B., and Gude V.G. (2015). Sustainable photosynthetic biocathode in microbial desalination cells. Chemical Engineering Journal, 262, 958-65. DOI: 10.1016/j.cej.2014.10.048

Luo H., Xu P., Jenkins P.E., and Ren Z. (2012). Ionic composition and transport mechanisms in microbial desalination cells.Journal of Membane Science, 409-10, 1623. DOI: 10.1016/j.memsci.2012.02.059.

Mardiana U., Innocent C., Cretin M., Buchari B., Setiyanto H., Nurpalah R., Kusmiati M. (2019). Applicability of Alginate Film Entrapped Yeast for Microbial Fuel Cell. Russian Journal of Electrochemistry, 55, 78-87. DOI:10.1134/S1023193519010075

Mardiana U., Innocent C., Jarrar H., Cretin M., Buchari B., Gandasasmita S. (2015). Electropolymerized neutral red as redox mediator for yeast fuel cell. International Journal of Electrochemical Science, 10, 8886-8898

Maritz J., Krieg H.M., Yeates C.A., Botes A.L., and Breytenbach J.C. (2003). Calcium alginate entrapment of the yeast Rhodosporidium toruloides for the kinetic resolution of 1 , 2-epoxyoctane. Biotechnology Letter, 20,1775-1781. DOI: 10.1023/a:1026044113856.

Meena K., and Raja T.K. (2006). Immobilization of Saccharomyces cerevisiae cells by gel entrapment using various metal alginates. World Journal of Microbiology and Biotechnology,22, 651-653. DOI:10.1007/s11274-005-90851.

Mehanna M., Saito T., Yan J., Hicjner M., Cao X., Huang X. and Logan B.E. (2010). Using microbial desalination cells to reduce water salinity prior to reverse osmosis. Energy and Environmental Science, 3, 1114-1120. DOI: 10.1039/c002307h.

Meng F., Jiang J., Zhao Q., Wang K., Zhang G., Fan Q., Wei L., Ding J., Zheng Z. (2014). Bioelectrochemical desalination and electricity generation in microbial desalination cell with dewatered sludge as fuel. Bioresource Technology, 157, 120126. DOI: 10.1016/j.biortech.2014.01.056.

Mulyono T., Misto, Busroni, Siswanto. (2020). Bioelectricity Generation from Single-Chamber Microbial Fuel Cells with Various Local Soil Media and Green Bean Sprouts as Nutrient. International journal of Renewable Energy Development, 9(3), 423-429. DOI: 10.14710/ijred.2020.30145

Pauliukaite R., and Brett C.M.A. (2008). Poly(neutral red): electrosynthesis, characterization, and application as a redox mediator. Electroanalysis, 20,1275-85. DOI: 10.1002/elan.200804217.

Qu Y., Feng Y., Wang X., Liu J., Lv J., He W., and Logan B.E. (2012). Simultaneous water desalination and electricity generation in a microbial desalination cell with electrolyte recirculation for $\mathrm{pH}$ control. Bioresource Technology, 106, 89-94. DOI: 10.1016/j.biortech.2011.11.045.

Saeed H.M., Husseini G.A., Yousef S., Saif J. (2015). Microbial desalination cell technology: A review and a case study. Desalination, 359, 1-13. DOI: 10.1016/j.desal.2014.12.024.

Sayed E.T., Tsujiguchi T., and Nakagawa N. (2012). Catalytic activity of baker's yeast in a mediatorless microbial fuel cell. Bioelectrochemistry, $\quad 86, \quad 97-101 . \quad$ DOI: 10.1016/j.bioelechem.2012.02.001.

Taher H., Al-Zuhair S., Al-Marzouqi A.H., Haik Y., and Farid M.M. (2011). A review of enzymatic transesterification of microalgal oil-based biodiesel using supercritical technology. Enzyme Research, 2011, 1-25. DOI: 10.4061/2011/468292.

Walker A.L., and Walker C.W. (2006). Biological fuel cell and an application as a reserve power source. Journal of Power Sources, $160, \quad 123-129 . \quad$ DOI: 10.1016/j.jpowsour.2006.01.077.

Wen Q., Zhang H., Chen Z., Li Y., Nan J., Feng Y. (2012). Using bacterial catalyst in the cathode of microbial desalination cell to improve wastewater treatment and desalination. Bioresource Technology, 125, 108-113. DOI: 10.1016/j.biortech.2012.08.140.

Werner C.M., Logan B.E., Saikaly P.E., and Amy G.L. (2013). Wastewater treatment, energy recovery and desalination using a forward osmosis membrane in an air-cathode microbial osmotic fuel cell. Journal of Membane Science, 428, 116-122. DOI: 10.1016/j.memsci.2012.10.031.

Yang C., Yi J., Tang X., Zhou G., and Zeng Y.(2006). Studies on the spectroscopic properties of poly(neutral red) synthesized by electropolymerization. Reactive and Functional Polymer, 66, 1336-1341. DOI:10.1016/j.reactfunctpolym.2006.03.015.

Yong Y.C., Liao Z.H., Sun Y.Z., Zheng T., Jiang R.R., and Song H. (2013). Enhancement of coulombic efficiency and salt tolerance in microbial fuel cells by graphite/alginate granules immobilization of Shewanella oneidensis MR-1. Process Biochemistry, 48, 1947-1951. DOI: 10.1016/j.procbio.2013.09.008.

Zhang H., Wen Q., An Z., Chen Z., and Nan J. (2016). Analysis of long-term performance and microbial community structure in bio-cathode microbial desalination cells. Environmental Science and Pollutan Research, 23, 59315940. DOI: 10.1016/j.biortech.2012.01.137. 